Patrick O. Aguiling, MD Nikki Lorraine Y. King-Chao, MD Lyra V. Veloro, MD ${ }^{1,2}$

'Department of Otorhinolaryngology Head and Neck Surgery

The Medical City

${ }^{2}$ Department of Child Neuroscience Section of Pediatric Otorhinolaryngology Philippine Children's Medical Center
Correspondence: Dr. Patrick Aguiling Department of Otolaryngology- Head and Neck Surgery The Medical City

Ortigas Avenue, Pasig City 1600 Philippines

Phone (632) 6356789 local 6250

Email: patrickaguiling@yahoo.com

Reprints will not be available from the author.

The authors declared that this represents original material that is not being considered for publication or has not been published or accepted for publication elsewhere, in full or in part, in print or in electronic media; that the manuscript has been read and approved by all the authors, that the requirements for authorship have been met by each author, and that each author believes that the manuscript represents honest work.

Disclosures: The authors signed disclosures that there are no financial or other (including personal) relationships, intellectual passion, political or religious beliefs, and institutional affiliations that might lead to a conflict of interest.

\title{
Congenital Maxillomandibular Fusion: A Rare Case of Isolated True Bony Syngnathia
}

\begin{abstract}
Objective: To present a rare case of congenital maxillomandibular fusion or syngnathia.
\end{abstract}

\section{Methods:}

\author{
Study Design: Case Report \\ Setting: Tertiary Public Teaching Hospital \\ Participant: One patient
}

Results: A 3-year-old girl with oral adhesion (syngnathia) caused by a mandibular to maxillary fibrous band with bony fusion underwent successful surgical division and release. Subsequent monitoring and serial oral dilations were performed post operatively, resulting in mouth opening of $24 \mathrm{~mm}$ over a period of three months. Currently, the patient is able to tolerate a general liquid diet.

Conclusion: Congenital maxillomandibular fusion is a very rare condition with few cases reported. We hope this report contributes to its diagnosis and management in other children.

Keywords: congenital maxillomandibular fusion, syngnathia

From birth, the upper aerodigestive tract of neonates plays an important role in simultaneous nose-breathing, suckling and swallowing. It is crucial for this mechanism to function properly to ensure survival. Problems that interfere with this design, such as bilateral choanal atresia, may result in death, unless attended to emergently. This report a case that could have had similar consequences over a slightly longer course.

\section{CASE REPORT}

A newborn girl from Nueva Ecija, Philippines was noted to have maxillo-mandibular fusion after full-term spontaneous home delivery to a 31-year-old G3P3 (3003) mother attended by a midwife. The mother was a non-smoker and non-alcoholic beverage drinker with irregular prenatal check-ups but had multivitamins and ferrous sulfate during pregnancy. She took unrecalled medications for an upper respiratory tract infection at 1 to 2 months of pregnancy and denied exposure to viral exanthems, chemicals, radiation or teratogenic drugs.

On examination, there was complete bilateral fusion of the bony upper and lower jaws. A nasogastric tube was inserted through the right nasal cavity. The rest of the physical examination findings were normal. Complete blood count revealed a white cell count of 18.45 with segmenter predominance. She was started on Ampicillin $60 \mathrm{mg} / \mathrm{IV}$ every 8 hours, Gentamicin $14 \mathrm{mg} / \mathrm{IV}$ 
CASE REPORTS

Philippine Journal Of Otolaryngology-Head And Neck Surgery

Vol. 28 No. 2 July - DeCEMBer 2013

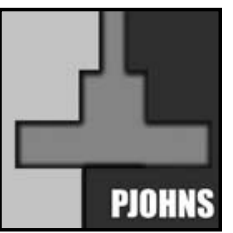

$\mathrm{OD}$, Vitamin $\mathrm{K} 0.5 \mathrm{mg} / \mathrm{IM}$ and Oxytetracycline eye ointment, and she eventuallyimproved. The assessment was congenital maxillomandibular fusion or syngnathia. (Figure 1)

CT scan of the facial bones with 3D reconstruction showed complete bony fusion of the maxilla and the mandible with hypoplasia of the temporomandibular joints. (Figure 2) Radiographs showed no definite lung infiltrates, cardiothymic shadow within normal limits, intact diaphragm and costophrenic angles, gastrointestinal tract patterns within normal, no abnormal mass or calcifications, no pneumoperitoneum or organomegaly and no osseous, joint space or soft tissue abnormalities appreciated.

At two months of age, elective tracheostomy under local anesthesia was performed due to dyspneic episodes associated with desaturations exacerbated by recurrent upper respiratory tract infections. Anesthesia was maintained through the tracheostomy tube while a gastrostomy was carried out. She tolerated the procedure well and was eventually discharged, breathing spontaneously and well oxygenated. Several follow-up visits included a repeat CT scan of the facial bones with 3D reconstruction (including reference markers) at 1 year and 5 months of age, but she was not seen again until 3 years of age.

At 3 years and 6 months of age, she underwent surgical division of the bony fusion. An extended right pre-auricular incision and dissection of the superficial temporal fascia over root of zygoma were carried to the fascia and periosteum which were incised over the zygomatic root. The skin flap and parotid were retracted anteriorly and the coronoid process and zygomatico-maxillo-mandibular area were exposed. With maximum retraction to facilitate optimal exposure of a long tunnel medial to the masseter muscle, the mandibular fusion was released and the mucosal incision was gradually extended to the midline. The bony fusion was exposed by dissecting the mucosa away from the bone using a periosteal and freer elevator. Osteotomy of zygomatico-maxillomandibular fusion was achieved by tunneling from the zygomatic area to the midline by alternately using an osteotome, oscillating saw and high-speed surgical drill with different-sized cutting bur tips. The same procedure was replicated on the left side up to the midline until the division from the right side was reached. The bony division was then pried open until all fibrous bands were detached. Sharp edges were smoothened using a surgical drill with diamond bur tips. Avulsed central and lateral incisors were removed. The oral cavity was established and packed with medicated gauze impregnated with antibiotic ointment. The patient underwent serial oral dilation on succeeding follow-ups, eventually achieving mouth opening of $24 \mathrm{~mm}$ within 3 months. (Figures $3,4)$ Currently, the patient is able to tolerate a general liquid diet.

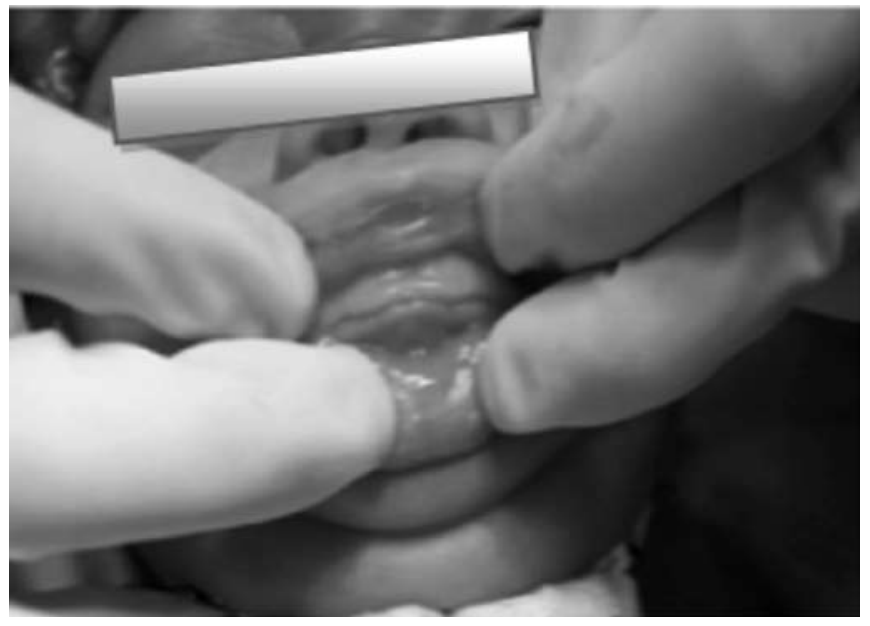

Figure 1. Complete bilateral fusion of the bony and soft-tissue components of the upper and lower jaws.

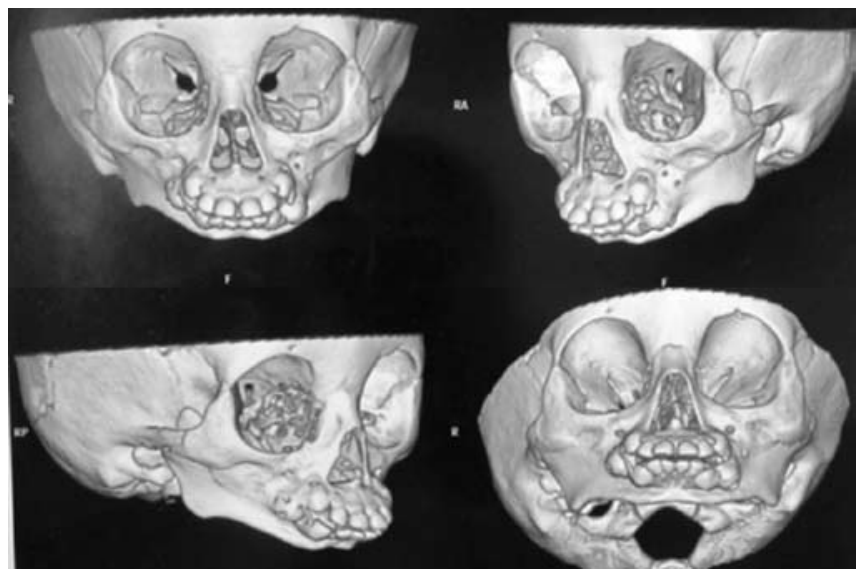

Figure 2. 3D reconstruction CT scan of the facial bones showing complete bony fusion of the maxilla and the mandible with hypoplasia of the temporomandibular joints.

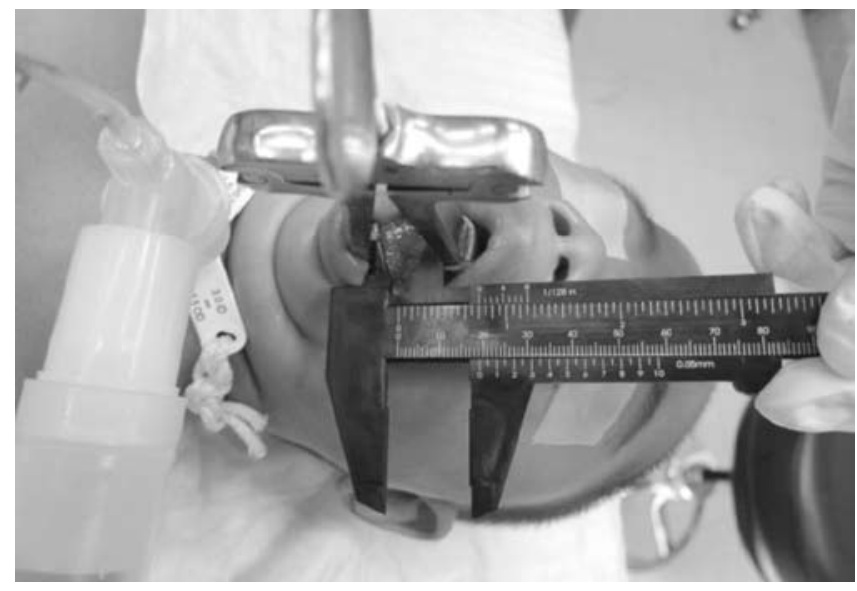

Figure 3. Oral dilation at $15 \mathrm{~mm}$ (4 weeks postoperative) 


\section{CASE REPORTS}

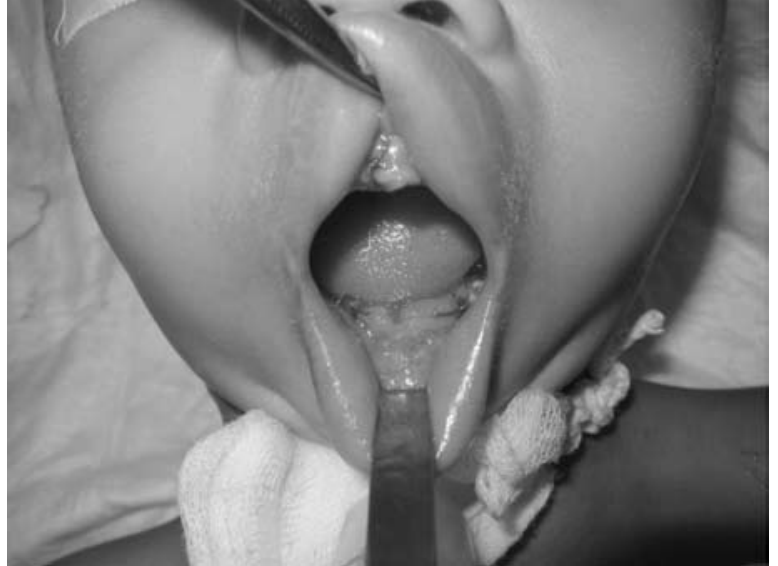

Figure 4. Mouth opening of $22 \mathrm{~mm}$ ( 8 weeks postoperative)

\section{DISCUSSION}

Congenital causes of limited mouth opening involving fusion of the maxilla and mandible (syngnathia) are a rare group of anomalies. Cases are classified into those involving bony tissue and those involving soft tissue alone. Occurrence may be unilateral or bilateral, partial or complete. ${ }^{1,2}$ Among the abovementioned classifications, cases involving solely soft tissue and bilateral fusion in the posterior region are more common. ${ }^{2}$

Isolated occurrence of bony syngnathia is a very rare condition with few reported cases. In the literature, the congenital defect is associated with other anomalies like Van derWoude syndrome, popliteal pterygium syndrome ${ }^{2,3}$ and aglossia-adactylia syndrome. Our patient has none of these syndromes or any other intraoral or maxillofacial abnormalities. No sex predilection has been reported. ${ }^{24}$ However, it is interesting to note that eight out of 11 cases reviewed for this study have male subjects.

The exact pathogenesis of congenital bony fusion is unknown. Some of the etiologic hypotheses proposed by Goodacre and Wallace ${ }^{5}$ include "persistence of buccopharyngeal membrane, amniotic constriction bands in the region of the developing first branchial arch, environmental insults, drugs such as meclozine and large doses of Vitamin A. ${ }^{11,2}$ According to a review by Dawson et al., there is no familial tendency, history of drug or toxin exposure and consanguinity. ${ }^{1,2,4}$ However, there is a possibility of autosomal recessive inheritance. Mir et al. and Poovazhagi et al. reported cases which revealed a history of consanguinity. ${ }^{1,6}$

Our patient presented with maxillomandibular fusion discovered immediately after birth. Physically, oral cavity deformity was evident and the baby was not able to open her mouth or feed normally. Once recognized, the diagnosis was confirmed by CT scan. These events are congruent with the observation that congenital bony fusion is clinically diagnosed soon or after birth as the neonate presents with airway and feeding difficulties. 'The modality of choice is high resolution or spiral CT scan which has the advantage of revealing the condition of the temporomandibular joints or any hypoplasia of the other facial bones.'

The usual accompanying problems in such patients include airway and respiratory impairment, feeding difficulties, speech limitation, poor oral hygiene, interference with salivation and mastication, and induction of anesthesia.' In spite of these complications, studies show that functional results especially in isolated occurrence are likely to be good.' For our patient, feeding problems were addressed initially by insertion of nasogastric tube and subsequently, by gastrostomy tube.

Treatment consists of surgical division of the maxillomandibular fusion under anesthesia. ${ }^{1,6}$ Awake blind nasal intubation is the ideal manner of inducing anesthesia, although a tracheostomy may be required if blind intubation fails. ${ }^{1,2} \mathrm{~A}$ less invasive technique using fiberoptic nasotracheal intubation may also be administered., ${ }^{3,6}$ Our patient underwent tracheostomy insertion for maintenance of airway and anesthesia. Following surgery, active physical therapy is recommended and the infant should be encouraged to feed normally as soon as possible ${ }^{1,3,4}$ to achieve adequate mandibular range or motion and function. Acceptable mouth opening may be appreciated 1-2 weeks post operatively. ${ }^{6}$ The mother of our patient was advised to perform such manual therapy techniques as carefully opening the baby's mouth with a tongue depressor and rotating fingers to press the gums.

Indeed, congenital maxillomandibular fusion is a very rare condition with few cases reported. We hope this report contributes to its diagnosis and management in other children.

REFERENCES

1. Mir M, lqbal S, Hafeez A, Zargar H, Rasool A, Mohsin M, Darzi A. Syngnathia without any other associated anomaly: A very rare case report. The Internet Journal of Plastic Surgery. 2006;4(1). Cited 2013 March 24. Available at:http://ispub.com/IJPS/4/1/13380.

2. Bali R, Sharma P, Jain S, Thapar D. Congenital fibrous maxillomandibular fusion. J Maxillofac Oral Surg. 2010 Sep; 9(3): 277-279.

3. Puvabanditsin S, Garrow E, Sitburana O, Avila FM, Nabong MY, Biswas A. Syngnathia and Van der Woude syndrome: a case report and literature review. Cleft Palate Craniofac J. 2003 Jan; 40(1): 104-6.

4. Dawson KH, Gruss JS, Myall RW. Congenital bony syngnathia: a proposed classification. Cleft Palate Craniofac J. 1997 Mar; 34(2):141-146.

5. Goodacre TE, Wallace AF. Congenital alveolar fusion. Br J Plast Surg. 1990 Mar; 43(2): 203-209.

6. Poovazhagi V, Vijayakumar V, Kumudha J, Balachandran K. Congenital fusion of maxilla and mandible (bony syngnathia). Pediatric Oncall 2009. Cited 2009 December 1; 6(12) Art 63. Available at http://www.pediatriconcall.com/fordoctor/casereports/syngnathia.asp 